\title{
126. Purification and Cloning of a Ribosomal RNA Gene Fragment from Mouse DNA
}

\author{
By Yukio Mishima, *) Masaharu SakaI,*) Masami Muramatsu,*) \\ Tohru KATAOKA,**) and Tasuku HoNJo**)
}

(Communicated by Toshio Kurokawa, M. J. A., Dec. 12, 1978)

Introduction. Since the advent of the cloning systems employing either plasmids or $\lambda$ phage, the isolation and characterization of a single gene from a eukaryotic genome has become a potent approach to the understanding of the complex mechanism of gene regulation in mammalian cells. Several eukaryotic genes from various species have already been isolated and characterized at least partially. We have also reported cloning of an immunoglobulin heavy chain gene from the newborn mouse (Honjo, 1978; Honjo, Kataoka, and Y-Kataoka, in preparation).

The genes coding for ribosomal RNA (rRNA) have been cloned from Yeast (Kramer et al., 1976), Drosophila (Thomas et al., 1974), Xenopus (Morrow et al., 1974), Mouse (Tiemeier et al., 1977) and Chicken (McClements and Skalka, 1977). For mammalian rRNA genes, however, the fragments so far obtained were only internal segments containing neither the promoter nor the terminator region. In order to study the regulatory mechanism of rRNA transcription, it is essential to isolate a fragment containing the 5 '-terminal region of the rRNA gene which would contain the promoter.

This work has been initiated for this purpose and, in this report, we describe a successful isolation of such a gene fragment from mouse DNA.

Materials and methods. High molecular weight DNA from newborn mice was prepared by a phenol-chloroform method as described elsewhere (Honjo et al., in preparation). The digestion of the mouse DNA with EcoRI, RPC-5 column chromatography and agarose gel electrophoresis were also described in the paper cited above. The detection of $18 \mathrm{~S}$ rRNA sequences was performed as described (Honjo et al., in preparation). The procedures of ligation and phage DNA preparation were as described by Tiemier et al. (1977). Introduction of DNA by in vitro packaging technique was carried out as

*) Department of Biochemistry, Cancer Institute, Japanese Foundation for Cancer Research, Tokyo.

**) Department of Physiological Chemistry and Nutrition, Faculty of Medicine, University of Tokyo, Tokyo. 
described (Becker and Gold, 1975; Hohn and Murray, 1977; Sternberg et al., 1977; Blattner, personal communication). Detection of the recombinant phage by in situ hybridization was essentially according to Benton and Davis (1977). Detection of the recombinant plasmid by in situ colony hybridization was done as described by Grunstein and Hogness (1975). Transformation of Escherichia coli LE392, a derivative of strain ED8656, by pBR322 ligated with rRNA gene fragments was done according to Enea et al. (1975). ${ }^{32} \mathrm{P}$ - or ${ }^{3} \mathrm{H}$-labeled complementary DNA (cDNA) of $18 \mathrm{~S}$ rRNA was prepared by reverse transcription with random oligonucleotide as described by Taylor et al. (1976). ${ }^{3} \mathrm{H}-\mathrm{cDNA}$ has been purified by incubating to a Cot of $10^{-2}$ and fractionating by a hydroxyapatite column. The specific activity of ${ }^{32} \mathrm{P}$ - and ${ }^{3} \mathrm{H}-\mathrm{cDNA}$ was $>1.0 \times 10^{8}$ and $1.0 \times 10^{7} \mathrm{cpm} / \mu \mathrm{g}$, respectively. All the cloning procedures were carried out in a P-2 laboratory according to the revised NIH Guidelines. This also conformed to the current recommendation by the Japanese Committee on Recombinant DNA.

Results and discussion. 1) Concentration of ribosomal RNA gene fragments containing the promoter region. Fig. 1 presents a diagram of the structure of ribosomal RNA genes of the mouse. When the mouse DNA was digested with a restriction endonuclease EcoRI, two categories of gene fragments were produced which could be identified with labeled rRNA probes (Arnheim and Southern, 1977). Although the smaller fragment containing parts of both $18 \mathrm{~S}$ and $28 \mathrm{~S}$ RNA was homogeneous in size $(\sim 6.6 \mathrm{~kb})$ the larger fragment containing only $18 \mathrm{~S} \mathrm{RNA}$ and the 5 -terminal region of the gene was rather heterogeneous (14-17 kb) suggesting sequence heterogeneity of the spacer region preceding the promoter.

In order to isolate the fragment containing the promoter region, approximately $40 \mathrm{mg}$ of newborn mouse DNA digested with EcoRI was fractionated by an RPC-5 column and each fraction tested for the presence of rRNA sequences after running on an agarose gel.

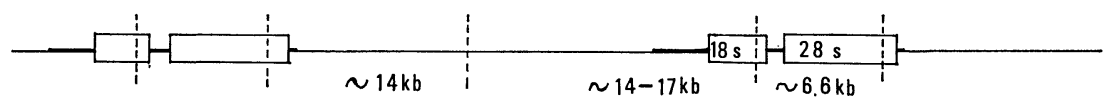

Fig. 1. Organization of ribosomal RNA gene of the mouse. Broken bars indicate the cleavage sites of restriction endonuclease EcoRI. Thick lines indicate the transcribed spacer of 45S-preribosomal RNA. $\mathrm{kb}$ : Kilobases.

The fractions containing $14-17 \mathrm{~kb}$ bands hydridizable with rRNA probe (data not shown) were pooled and used for cloning. The general scheme for the cloning is summarized in Fig. 2. 


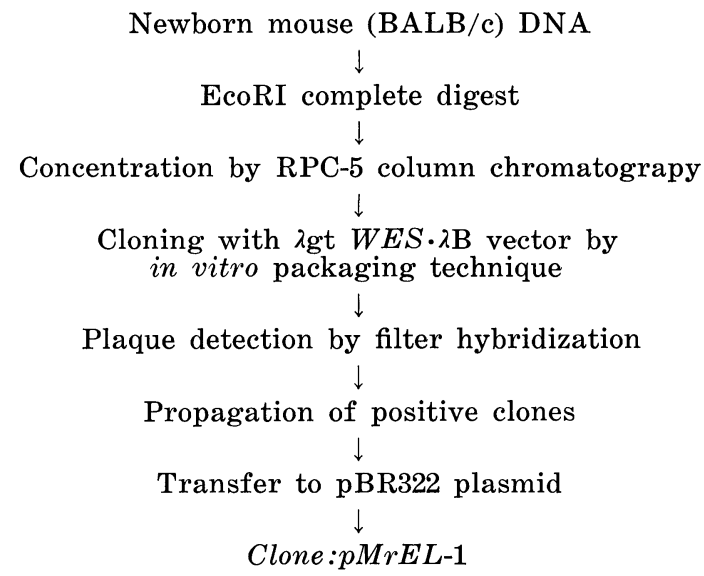

Fig. 2. Scheme of rDNA Cloning.

2) Cloning and screening of Ribosomal RNA gene fragments. The DNA fragments partially purified with respect to ribosomal RNA sequence as described above were ligated in vitro with two outer fragments of a mutant coliphage lambda ( $\mathrm{gt} W E S \cdot \lambda \mathrm{B})$ and transfected into a mutant strain of Escherichia coli (LE392). We used the in vitro packaging method for the cloning of these DNA fragments,

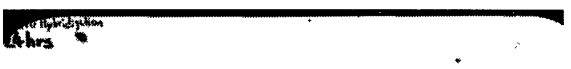

Fig. 3. Detection of hybrid clones. Approximately 2,000 phage clones were transferred to each filter. Detection of 18S rRNA gene was carried out by hybridization with ${ }^{32} \mathrm{P}-18 \mathrm{~S}-\mathrm{cDNA}$ followed by autoradiography. The arrow indicates the recombinant clone $\sharp 3$. 
Table I. Presence of $18 \mathrm{~S}$ rRNA sequence in clone $\# 3$ DNA

\begin{tabular}{lc}
\hline Input $\left({ }^{3} \mathrm{H}-18 \mathrm{~S}-\mathrm{cDNA}\right)$ & $100 \%$ \\
$\mathrm{~S}_{1}$-Nuclease treated & 0 \\
18S rRNA & 97.9 \\
$\sharp 3$ & 47.4 \\
$\# 7$ & 1.7 \\
\hline
\end{tabular}

Percentages of the input counts $(564 \mathrm{cpm})$ were shown. S $\mathrm{S}_{1}$-unclease-treated ${ }^{3} \mathrm{H}-\mathrm{cDNA}$ count $(45 \mathrm{cpm})$ was subtracted from each counts.

because it showed a much higher $\left(>10^{2}\right)$ transfection efficiency than ordinary $\mathrm{Ca}^{2+}$ method in our preliminary experiments.

Approximately 20,000 phage plaques were screened by in situ hybridization using ${ }^{32} \mathrm{P}$-labeled $\mathrm{cDNA}$ of $18 \mathrm{~S}$ rRNA as a probe. Six out of twelve positive spots obtained (Fig. 3) were picked up and separately propagated in a small scale $(2 \mathrm{ml})$ to prepare DNA, which was then tested for the presence of $18 \mathrm{~S}$ rRNA sequence both by liquid hybridization and by Southern technique after digesting with EcoRI.

Although all the clones were positive with ${ }^{32} \mathrm{P}-\mathrm{cDNA}$ of $18 \mathrm{~S}$ rRNA, one of the clones named \#3 was further examined using Cotpurified ${ }^{3} \mathrm{H}-\mathrm{cDNA}$ (see Materials and methods) as a probe. Table I shows the clone \#3 DNA hybridized with $47.4 \%$ of input cDNA, whereas clone \#7 DNA which had not hybridized originally, did not hybridize with ${ }^{3} \mathrm{H}-\mathrm{cDNA}$ at all. These results indicate that clone \#3 DNA does contain nearly half of the $18 \mathrm{~S}$ rRNA sequence.

3) Re-cloning of the clone \#3 DNA into pBR322. On examination by gel electrophoresis, clone \#3 was found to be contaminated wit hanother clone containing a $7.4 \mathrm{~kb}$ fragment of mouse DNA. It has also been known that phage DNA having a large inserted DNA fragment tends to cause deletions during growth. In addition, the ribosomal DNA fragment contained in clone \#3 had a size (14-15 kb) which was rather hard to separate from the DEF fragment of $\lambda \mathrm{gt}$ $W E S$ by agarose gel. To solve these problems, we tried to transfer the

Table II. Presence of 18S rRNA sequence in recloned \#3 DNA-pBR322-recombinant

\begin{tabular}{lrl}
\hline Input $\left({ }^{3} \mathrm{H}-18 \mathrm{~S}-\mathrm{cDNA}\right)$ & 100 & $\%$ \\
$\mathrm{~S}_{1}$-Nuclease treated & 0 & \\
18S rRNA & 72.3 & \\
Clone $\#(1-4)$ & 48.8 \\
\hline
\end{tabular}

Precentages of the input counts $(749 \mathrm{cpm})$ that were resistant to $S_{1}$-nuclease were shown. $S_{1}$ nuclease treated ${ }^{3} \mathrm{H}-18 \mathrm{~S}-\mathrm{cDNA}$ counts $(56 \mathrm{cpm})$ was subtracted from each counts. 
fragment in clone \#3 into a plasmid pBR322 DNA in which the inserted DNA was supposed to be more stable and could be recovered more easily.

Clone \#3 DNA was digested with EcoRI and the fragments were ligated with pBR322 DNA which had been cleaved with the same enzyme and treated with alkaline phosphatase. Among 60 colonies screened, one positive clone numbered as \#(1-4) was obtained. The existence of 18S rRNA sequence was examined by liquid as well as filter hybridization. The results shown in Table II indicate that this clone actually contains roughly half of the $18 \mathrm{~S}$ rRNA sequence. To demonstrate that the size of the cloned rRNA gene fragment was the same as that originally concentrated and picked up, the recombinant plasmid DNA was digested with EcoRI, electrophoresed on an agarose gel and examined by the Southern blotting technique (1975). As seen in Fig. 4, whereas the DNA in an originally pooled DNA fraction (\#30) contained somewhat heterogeneous bands ranging from 14 to $17 \mathrm{~kb}$, the cloned DNA \# (1-4) digested with EcoRI showed a single band of approximately $14 \mathrm{~kb}$ which was hybridized with cDNA complementary to $18 \mathrm{~S}$ rRNA. This band did not hybridize with the cDNA

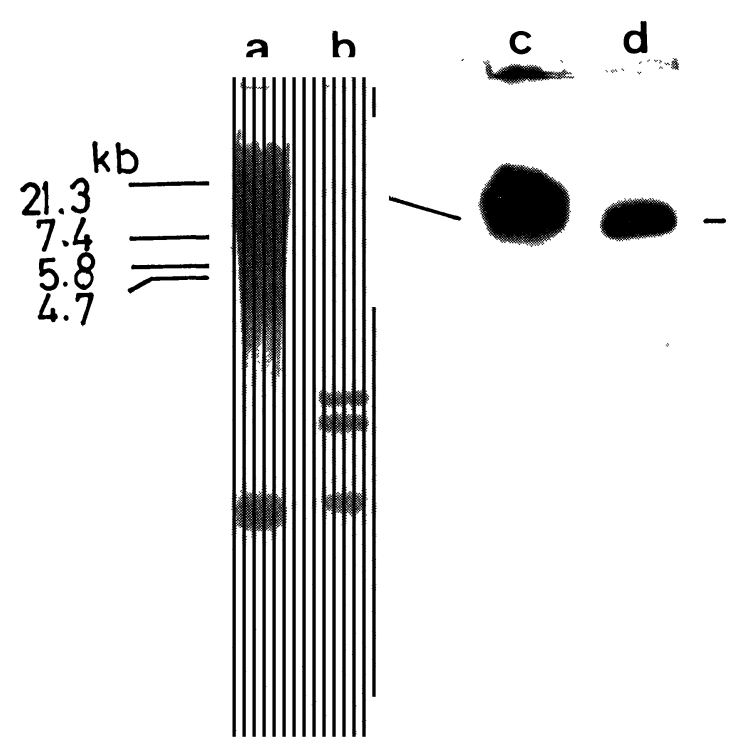

Fig. 4. Presence of $18 \mathrm{~S}$ rRNA sequence in clone $\#(1-4)$. (a, b) shows the ethidium bromide-stained $1 \%$ agarose gel and $(c, d)$ represents the autoradiography which was hybridized with ${ }^{32} \mathrm{P}-18 \mathrm{~S}-\mathrm{cDNA}$. DNA of columns (a) and (c) was the fraction $\# 30$ of RPC-5 column chromatography containing the $14-17 \mathrm{~kb}$ rDNA fragment. DNA of column (b) and (d) was EcoRI-digested \#(1-4) plasmid clone. EcoRI fragments of $\lambda$ CI857 were used as size markers. 
complementary to $28 \mathrm{~S}$ rRNA (data not shown). This recombinant plasmid containing a part of $18 \mathrm{~S} r \mathrm{RNA}$ sequence and most probably a promoter region of an rRNA gene of the mouse was designated pMrEL-1.

While this study was under way, we recieved a personal communication that M. H. Edgell at the University of North Carolina had obtained a similar clone from the mouse.

Summary. Newborn mouse DNA was digested with a restriction endonuclease EcoRI and concentrated with respect to ribosomal RNA sequences by an RPC-5 column.

DNA fragments of 14-17 kilobases in length, most probably containing promoter region of the ribosomal RNA gene, were used for cloning with $\lambda$ gt $W E S \cdot \lambda \mathrm{B}$ as a vector using an in vitro packaging technique. Several clones containing $18 \mathrm{~S}$ rRNA sequences were obtained. One of the clones which was transferred to a plasmid pBR322 (designated as pMrEL-1) was 14 kilobases in length, having only a part of $18 \mathrm{~S}$ rRNA sequence. These results strongly suggest that this fragment carries a promoter region of the ribosomal RNA gene.

Acknowledgements. We thank Dr. P. Leder, NIH, USA, for his generous gift of $\lambda \mathrm{gt} W E S \cdot \lambda \mathrm{B}-\mathrm{LE} 392$ vector-host system used in this study. We also thank Professor Y. Mano, University of Tokyo, for continuous encouragement. This investigation was supported in part by grants from Ministry of Education, Science and Culture of Japan.

\section{References}

Arnheim, N., and Southern, E. M. (1977) : Cell, 11, 363-370.

Becker, A., and Gold, M. (1975) : Proc. Natl. Acad. Sci. U.S.A., 72, 581-585.

Benton, W. D., and Davis, R. W. (1977) : Science, 196, 180-182.

Enea, V., Vovis, G. F., and Zinder, N. D. (1975) : J. Mol. Biol., 96, 495-509.

Grunstein, M., and Hogness, D. S. (1975): Proc. Natl. Acad. Sci. U.S.A., 72, 3961-3965.

Hohn, B., and Murray, K. (1977) : Proc. Natl. Acad. Sci. U.S.A., 74, 3259-3263.

Honjo, T. (1978) : Immunology '78 (eds. Yamamura, Y., and Tada, T.). Nakayama Shoten, Tokyo, pp. 75-82.

Kramer, R., Cameron, J., and Davis, R. (1976) : Cell, 8, 227-232.

McClements, W., and Skalka, A. M. (1977) : Science, 196, 195-197.

Morrow, J. F., Cohen, S. N., Chang, A. C. Y., Boyer, H. W., Goodman, H. M., and Helling, R. B. (1974) : Proc. Natl. Acad. Sci. U.S.A., 71, 1743-1747.

Sternberg, N., Tiemeier, D., and Enquist, L. (1977) : Gene, 1, 255-280.

Southern, E. M. (1975) : J. Mol. Biol., 98, 503-517.

Taylor J. H., Illmensee, R., and Summers, J. (1976) : Biochim. Biophys. Acta, 228, 324-330.

Thomas, M., Cameron, J., and Davis, R. (1974) : Proc. Natl. Acad. Sci. U.S.A., 71, 4579-4583.

Tiemeier, D. C., Tilghman, S. M., and Leder, P. (1977) : Gene, 2, 173-191. 